[Higgins, J. (2003). The Numeracy Development Project: Policy to Practice. New Zealand Annual Review of Education, 12, 157-175]

\section{The Numeracy Development Project: Policy to Practice}

\section{JOANNA HigGINS WITH RO PARSONS AND MALCOLM HYLAND}

\section{Abstract:}

The Numeracy Development Project has been heralded as an example of successful transformation of policy to practice. Evidence of raised student achievement and improved teacher knowledge has been reported for three consecutive years for the Early and Advanced Numeracy Projects (see Thomas $\mathcal{E}$ Ward, 2001, 2002; Thomas, Tagg, \& Ward, 2003; Higgins, 2001, 2002a, 2003 a for a full account). Major factors in the success of the implementation of this policy include on-going evaluation, a developing research base from the findings, and the promotion of the concept of a learning community. This article is a descriptive analysis of the Numeracy Development Project using Rist's (1998) framing of the policy process and Patton's theory of utilization-focused evaluation. It discusses the different interdependent and interrelated aspects of policy formulation, implementation and evaluation that comprise a dynamic approach to the policy process.

$\mathrm{T}$

homas and Ward (2002) begin their 2001 evaluation of the Early Numeracy Project by noting "A feature of the Numeracy

Development Project is its dynamic and evolutionary approach to implementation." The development of the Ministry of Education's numeracy policy provides an interesting case study of the relationship between evaluation, research and policy. "The project continues to be informed by developing understandings about students' learning of number and what constitutes effective professional development and effective facilitation" (Thomas \& Ward, 2002, p. ii). The continued involvement of the mathematics learning community in developing policy ensures that links are developed between knowledge and action in terms of the end-users of the policy in classrooms. This article will examine the key components of this dynamic and evolutionary approach.

\section{Joanna Higgins}

\section{Phases in the Policy Cycle}

This analysis of the Numeracy Development Project as policy formation makes use of Rist's (1998) redefinition of decision-making in policy creation through a close examination of the policy cycle. Rist saw the formation of policy as a multidimensional and multifaceted evolutionary process and was particularly interested in the linkage between knowledge and action. He described policy making as a process that:

... evolves through cycles, with each cycle more or less bounded, more or less constrained by time, funds, political support, and other events. It is also a process that circles back on itself, iterates the same decision issue time and again, and often does not come to closure. Choosing not to decide is a frequent outcome. (Rist, 1998, p. 402)

Rist also commented on ways in which qualitative research can influence the policy process:

Research can contribute to informed decision making, but the manner in which this is done needs to be reformulated. We are well past the time when it is possible to argue that good research will, because it is good, influence the policy process. That kind of linear relation of research to action simply is not a viable way in which to think about how knowledge can inform decision-making. The relation is both more subtle and more tenuous (pp. 401-02).

Patton's (1997) work on utilization-focused evaluation also links knowledge and action. He advocates working with the intended users (such as policy-makers and the participants) of an evaluation to identify and then achieve their intended uses. He coined the term "process use" to highlight the nature of the impact on those involved in an evaluation. Patton identified three primary uses of evaluation findings. He saw the linear relation of research to action as serving the purpose of judging the merit or worth of a programme. He contrasted this with evaluations that facilitate improvements through their formative nature and their situation within a learning community, and those evaluations that generate knowledge through generalizations about effectiveness and use in policy making.

Previous evaluations of New Zealand mathematics programmes (for instance, those associated with the introduction to schools of the NZ Curriculum Framework, Ministry of Education, 1993, and the mathematics curriculum statement, Ministry of Education, 1992) 
occurred at the conclusion of a programme of professional development (Gilmore, 1994). The summative nature of these evaluations limited their impact on the formulation of policy for mathematics programmes. Rist (1998) argued that by redefining decision-making as "an ongoing set of adjustments, or midcourse corrections, [this] eliminates the bind of having to pinpoint the event - that is, the exact time, place, and manner - in which research has been influential on policy" (p. 403). The process followed in the Numeracy Development Project is a good illustration of Rist's definition of policy as an iterative, developmental process involving a learning community.

\section{Broad Parameters of Government Action}

While the last two to three years have seen teachers and schools make, in many cases, substantial changes to the delivery and organization of mathematics (in particular number) programmes in the first eight years of primary school (Higgins, 2001, 2002a, 2003a; Irwin \& Neiderer, 2002; Irwin, 2003; Thomas \& Ward, 2001, 2002; Thomas, Tagg, \& Ward, 2003), these changes have a longer history in terms of policy development.

Recent changes to primary mathematics programmes can be traced back to 1994 with the publication of the report Mathematics in the New Zealand Curriculum (Education Review Office, 1994). This report raised concerns about the extent to which the then new curriculum gazetted in 1992 was being implemented. A report commissioned by the Ministry of Education and carried out by Professor Derek Holton and others also highlighted difficulties experienced by teachers (Holton et al., 1996). Teachers reported that they found difficulties in the problem solving approach required by the curriculum statement (Ministry of Education, 1992). The publication of the results of the Third International Mathematics and Science Study (TIMSS) (Garden, 1997) identified the achievement of New Zealand students as being significantly below international means. New Zealand students performed poorly in number (place value, fractions, computation), measurement, and algebra concepts. As a result of the TIMSS findings, questions were raised about teachers' personal knowledge of mathematics. The National Education Monitoring Project (NEMP) mathematics assessment results also highlighted deficiencies in students' performance (Flockton \& Crooks, 1997).

In 1997 the Government established the Mathematics and Science Taskforce, in response to the TIMSS results, and feedback from the mathematics community about difficulties in implementing the 1992
160 Joanna Higgins

curriculum. This was similar to action taken by governments in other English-speaking countries whose students produced dismal results compared to those of students from Asian countries. Accordingly, the role of the Taskforce was to provide advice on how to improve the teaching of mathematics and science in New Zealand schools, and to identify "the kind/level of support that classroom teachers need to make the curriculum reforms in maths and science work" (Ministry of Education, 1997, p. 1). The Taskforce highlighted a number of overriding priorities in relation to raising performance in mathematics. These included:

- the need to raise teachers' and parents' expectations of success;

- the need to improve the professional skills, knowledge and confidence of teachers;

- the need to provide resources and professional development for teachers to assist and support them in implementing the curriculum;

- the need to lift Māori and Pacific Islands students' levels of achievement.

The mathematics sub-group of the Taskforce recommended that the initial focus of any additional intervention should be to provide help for teachers of the five- to nine-year-old age group. They also suggested that teacher support material should initially focus on the number concepts (including place value) across all mathematics curriculum strands and that the next priority areas should be algebra and measurement. An important component of the provision of support for teachers was recommendation for the implementation of school-based professional development programmes. In identifying priorities for long-term action, the mathematics sub-group also argued the need to implement research programmes, address issues associated with recruitment and training of teachers, and raise the profile of mathematics in the community.

Rist (1998) saw "the setting of [such] national priorities [as] a political event, a coming together of a critical mass of politicians, special interest groups, and persons in the media who are able among them to generate the attention and focus necessary for the items to reach the national agenda" (p. 404). The process of setting national priorities for numeracy, described above, followed such a pattern, and culminated in the Government's adoption of a literacy and numeracy goal in 1998. The goal was that, "By 2005, every child turning nine will be able to read, write 
and do maths for success." The subsequent revision of the National Administration Guidelines (Ministry of Education, 2000) gave impetus to the work that followed through the requirement to give priority to "student achievement in literacy and numeracy especially in years 1 to 4 ".

\section{The Policy Cycle}

With the political agenda set, the policy cycle begins. Phases in the cycle are not time-bound, but exist concurrently. Rist (1998) refers to the second level of policy making as the translation of policy intentions into "policy and programmatic realities" using the three-phase cycle of policy formulation, policy implementation, and policy accountability (or evaluation). Rist's justification for examining policy under these three phases is that:

Each of these three phases has its own order and logic, its own information requirements, and its own policy actors. Further, there is only some degree of overlap among the three phases, suggesting that they do merit individual analysis and understanding. (Rist, 1998, p. 405)

From the beginning of the policy cycle, academics, teacher educators, national and regional coordinators, facilitators, principals and teachers were involved as policy actors who both contributed to, and were users of, the policy as it evolved (Patton, 1997).

\section{The Formulation Phase}

Early steps in the initial policy formulation phase of the cycle set the focus on professional capability. It is important to note here that the process of clarifying the focus continues to go through much iteration, but the initial phase drew on the evidence base in existence at that time. Rist (1998) suggested that three broad sets of questions were important in the formulation phase. The first set of questions helps to define the problem. In the case of the Numeracy Development Project this was about low student achievement, and poor teacher knowledge of mathematics (Garden, 1997). The second set of questions focuses on previous attempts to respond to the problem. The third set of questions is around what and how these previous responses could be used in the current formulation of policy. This last phase is often intense as a government needs to be seen to respond swiftly to an identified problem. As Rist has pointed out, the generally short time frame restricts this phase to information already in existence rather than relying on specially commissioned studies to investigate the problem. Therefore the Ministry of Education used a multi-pronged approach to defining the problem. The focus on professional capability provided the order and logic for the formulation phase. The TIMSS results indicated the need to lift student achievement in mathematics, and the Mathematics and Science Taskforce highlighted the need to improve the knowledge, skills and confidence of teachers.

In 1998 the Ministry of Education commissioned literature reviews in response to issues identified by the Mathematics and Science Taskforce (Else, 1999). A research seminar on mathematics education was convened in June, 1998 to discuss what could be used from previous attempts to solve the problem of teacher capability. This was useful in defining the problem, as well as in exploring previous attempts to respond to the question. Key issues in mathematics education were identified as developing teachers' pedagogical content knowledge; improving teaching quality and confidence; providing resources to support mathematics teaching and learning; making research information more readily available and accessible to teachers; and emphasising the importance of mathematics education prior to school entry. Information on the current state of mathematics education for teachers in both New Zealand and overseas was required for the formulation of policy based on evidence.

Early in the policy cycle the Ministry recognised that the issues identified in mathematics education could not be addressed by the Ministry alone. This led to sector involvement, which was a deliberate strategy for the inclusion of the mathematics community as policy actors. The relatively cohesive nature of the mathematics education community and the willingness of its members to contribute to policy development made this process easier.

The extent of this involvement in terms of the Numeracy Development Project can be seen in the work of a number of specialist groups whose membership included practitioners, teacher educators, policy analysts and researchers. Each of the groups had a specific focus that contributed to clarifying the overall strategy on building professional capability. These groups (some of which are on-going) include:

- Junior Mathematics Review Group (1999)

- Numeracy Think Tank (1999-2000)

- Numeracy Development Project Working Group (2000-) 
- Numeracy Development Project Reference Group (2000-)

- BSM Review Group (2001)

- $\quad$ Te Rōpu Whāiti (Māori-medium Working Group) (2001-)

The groups all reinforced the Ministry's focus. They also enabled policy to be based on available research information by drawing on observation, action research and anecdotal evidence gathered in the field during the carrying out of the Numeracy Development Project, together with formal project evaluations.

The Taskforce had recommended that the initial focus of the Numeracy Development Project should be on the early years of schooling. The Ministry responded by setting-up the Junior Mathematics Review Group. The recommendations of this group were grounded in current research about children's early learning in mathematics and by group members' expertise and experience in professional development and mathematics education.

The Ministry of Education then convened a specialist group, the Numeracy Think Tank, late in 1999. The task of this group was to develop a New Zealand Number Framework (a novel idea for New Zealand) and an associated diagnostic tool (as recommended by the Junior Mathematics Review Group) that outlined for teachers key stages of number understanding against which they could chart the achievement of students in their class. It was important that the framework and the diagnostic tool were appropriate for the New Zealand context, but that they did not ignore international and national research on the development of children's understanding of number and the associated development of number frameworks (Higgins, 2001; Thomas \& Ward, 2001).

The Taskforce recommended a professional development programme for teachers of Year Three mathematics to take place in 1998/1999. The Auckland College of Education had included number knowledge frameworks in its Year Three professional development. This led to interest in an Australian project, Count Me In Too (Department of Education and Training, NSW, 1998) based on the work of Dr Bob Wright (1998). The demonstrated success of the programme in Australia (Bobis, 1999) led to a decision to consider the programme for New Zealand, and resulted in discussions between New Zealand and Australian officials and mathematics educators associated with the programme.

Strategies such as overlap and continuity of membership of the various groups described above were put in place. The activities of other educational agencies such as the Education Review Office and pre-service education and training providers such as colleges of education were incorporated in the Numeracy Development Project through inclusion in the various groups. While the Numeracy Development Project is nested within the government's Literacy and Numeracy Strategy, links exist also with other strategies such as the Assessment Strategy and the development of exemplars, and the Numeracy Assessment Tools. There are also links with Ministry initiatives such as the Curriculum Stocktake, website development, and curriculum support materials development.

\section{The Implementation Phase}

The policy makers needed to keep several aspects of education in mind. The review of the mathematics education literature was salient in the early stages of the project. There were other important bodies of literature. The findings of effective teaching (Askew et al., 1997), teacher learning, professional development (Darling-Hammond \& Sykes, 1999; Parsons, 2001; Putnam \& Borko, 1997), and education change (Fullan, $1999,2001)$ all helped to refine the focus of the implementation phase. Key concepts or policy artifacts such as the number framework and the associated diagnostic interview initially developed as part of the policy formulation, were incorporated in the implementation.

The implementation phase began in 2000 with a national pilot of Count Me In Too for Years 1 to 3 (Thomas \& Ward, 2001). A Years 4-6 exploratory study in the same year was originally conceived as a trial of the Australian Counting On programme. This programme did not turn out to be entirely suitable for New Zealand conditions. A desire to ensure continuity across Years 1-8 led to the trialling of the extended number framework as part of the implementation process (YoungLoveridge \& Wright, 2002).

An important feature of the pilot and the exploratory study was the focus on the professional development programme. This was subsequently reviewed and refined. The modification of the National Administration Guidelines (Ministry of Education, 2000) to emphasise literacy and numeracy required the definition of numeracy. This definition was also needed to establish links between the Numeracy Development Project and Mathematics in the New Zealand Curriculum (Ministry of Education, 1992). A working group of the Numeracy Development Project Reference Group carried out this work. The definition was debated and approved by the Numeracy Development 
Project Reference Group and subsequently published (Ministry of Education, 2001).

While there have been obvious resourcing constraints, the infrastructure is designed to support quality implementation. The implementation of the project is contracted by the Ministry of Education to the six major teacher education providers. The contract requirements in relation to outcomes are specific and rigorous. Each provider appointed a team of facilitators led by a regional coordinator. The different areas of the project (Years 1-3, Years 4-6, Years 7-10) are nationally coordinated and include on-site visits to the regional teams and regular regional meetings. All facilitators participate in six days national training each year and extra support for new facilitators is provided. Regional contracts provide formal mechanisms for managing the process. These include milestone reporting, national and regional meetings of facilitators, and evaluation of national and regional facilitator training by those participating. The quality of implementation is monitored closely by the Ministry through analysis of project milestone reports, visits by the national coordinator to all facilitators and feedback to the Ministry of Education by all those involved in implementing the programme. Informal mechanisms include the provision of professional readings to all facilitators, an opportunity to share experiences as the programme has proceeded, and the inclusion of aspects of the project in initial teacher education courses. Facilitators have been involved in development of materials for use in classrooms. The initial draft nature of these materials underscores the evolutionary approach to policy development. The structure of the programme to be delivered to teachers is set within broad parameters, but facilitators have sufficient flexibility to respond to the various contexts within which they are working. One of the facilitators explained how the tension between the structure of the programme and the professional development model played out in her work with teachers:

There is a very specific role that I have this year that's not necessarily how I would see a facilitator in general. Like I see that this is a very structured project. And I think sometimes I feel it is difficult being a facilitator of this project because it is so structured .... I want to know what [teachers'] needs are but having said that I recognise there are certain things we are asking them to do and it's non-negotiable basically.... It's allowing them to see the content that they need to be planning and teaching and it gives them a lot more understanding in terms of their own mathematics. So I see that there are a lot of different things that I am trying to achieve out of my role. (Higgins, 2002a, p. 53)

Although the implementation phase existed concurrently with the phases of policy formulation and policy accountability (or evaluation), the phase was distinguished by the order and logic arising from the nature of the infrastructure set up. This involved the alignment of different aspects of the policy process through formal and informal mechanisms. While the policy actors and the policy artifacts are the same in this phase as for the other two phases, the difference lies in the recognition that facilitators should play a key role in mediating the policy for teachers. Evidence from one of the facilitators involved suggested that they understood their role in the implementation phase as a mediator of policy:

The comment that has come back from teachers is that this contract has been so different and so successful because we can walk the walk, not just talk the talk. And so as facilitators we are the bridge between these Ministry policies and these Ministry initiatives, and what the broad things are in this curriculum and the actual how-to at a very down-to-earth, practical, ... classroom [level]. How do I actually plan my week, what do I actually put on paper, what resources do I use, what have you tried that's been effective?

Talking to teachers at a really practical level about how to implement it has been really critical. (Higgins, 2002a, p. 70)

The implementation of the Numeracy Development Project has been a success on a number of levels. Perhaps the key factors are the explanatory framework (Ministry of Education, 2002) that gives direction for responding effectively to children's learning needs and the use of the diagnostic interview that focuses on children's mathematical thinking. One of the facilitators involved in the project described the impact on teachers of the diagnostic interview:

One of the most essential triggers is that initial diagnostic assessment. That came through loud and clear when I asked for feedback. ... The comment over and over and over again, overwhelmingly, was that doing that diagnostic assessment changed something for [teachers] because first of all they were given time, the time to actually sit with their students and for so many of them it was an eye-opener.... So in general teachers felt confirmed that they had professionally made some pretty good judgements about the levels that their children were working at in number. But having said 
that there were always surprises and that was really revealing for those teachers and it was disquieting for them because it meant that they had to re-evaluate sometimes a child very seriously. (Higgins, 2002a, p. 54)

Another important aspect was that the professional development took place in the teacher's classroom. The facilitators were able to build a link with the intended programme and help teachers to modify their pedagogical practice. Again a facilitator's comment, that was typical of many, illustrates this point:

A most effective thing that this contract has done is to be in [the teacher's] classroom with their children modelling what it looks like and what's possible. We model with their kids and they say "I never knew that kid knew that" or "this is where this is coming from". I think the effective thing has been being in there facing their classroom and the fact that you keep on coming back.... you are able to talk with the teacher ... not just show what the activity is but talk about underlying concepts. ... We are modelling the mathematical questions, "so how do you know that?" and "what were you thinking?" and "I can hear Jo that you know those doubles but how did you know that double became that bit of the fraction?" (Higgins, 2002a, p. 58)

The structure and operation of the project have displayed a combination of top-down mandates and bottom-up energies (Fullan, 2001). Bottom-up energies have been exemplified by the work of coordinators, facilitators and teachers in all the development work related to resources such as guidelines, classroom activities and videos. The learning community that has developed around the project is characterised by high levels of trust, confidence and ownership. Leadership of various aspects of the project implementation is shared so that those involved (including Ministry personnel) work to their strengths. Contribution is valued. Conflict and challenge are not viewed as threatening, but as leading to new insights. The provision of regular opportunities to meet on a regional and national basis fosters open communication, collaborative practice, the sharing of new ideas and celebration of success. National gatherings involve workshop components, modelling of best practice in teaching, reflection on evaluation findings, and increasingly, a focus on the academic basis of various aspects of the project. The Numeracy Development Project Reference Group provides ongoing advice and critique in relation to the project.
The rapid growth of the project has highlighted the importance of articulating a vision, sharing the history and underpinnings of project development with the people involved. The emphasis on learning and continuous inquiry at every level sustains participants' energy and involvement. New knowledge has been generated in each component of the project. For example, project materials have been published in draft form in 2001 and 2002. Evaluation is an integral part of the policy process. As the project proceeds, the depth of community knowledge has increased through the preparation and presentation of conference papers and keynote addresses (For example: Anthony \& Walshaw, 2003; Higgins, 2002b, 2003b; Hughes, 2002; Hughes \& Peterson, 2003; Thomas, Tagg \& Ward, 2002; Wright, 2003; Young-Loveridge \& Wright 2002; Young-Loveridge \& Taylor, 2003).

\section{Policy Evaluation}

Underlying all programme evaluation is its political imperative (Greene, 1998; Patton, 1997; Rist, 1998). This shapes the questions asked, the target audience and the overall focus. The numeracy evaluations have used an interpretivist ideology grounded in a pragmatic philosophy (Greene, 1998). They have used a range of methods, both qualitative and quantitative. The key audiences have included policy makers, policy implementors, and school communities. The questions asked have ranged from those concerned with the quality and effectiveness of the programme in terms of its goals, and those that seek to find out how the programme has been experienced by those involved.

Patton (1997) argued that it is important for evaluators to clarify the intended uses of a particular evaluation and suggested an evaluation be judged by "intended use by intended users" (p. 63). The use made of the findings of the evaluations of the Numeracy Development Project fits within the three primary uses suggested by Patton.

The strength of this evidence is that the data collection is part of the project implementation (Patton, 1997). Patton termed this process "intervention-orientated evaluation to make explicit the direct and integral connection between data collection and program results." Examples of using the evaluation findings to judge the merit or worth of the programme include accountability for the money invested in schools by the government and deciding the programme's future. Is it working? Is it worth continuing? A key means of judging success has been the student results on the diagnostic interview. Evidence of success has, and continues to be, collected alongside the implementation of this policy. 


\begin{tabular}{|ll|}
\hline \multicolumn{1}{|c|}{ Three Primary Uses of Evaluation Findings } \\
\hline Uses & Examples \\
\hline Judge merit or worth & Summative evaluation \\
& Accountability \\
& Audits \\
& Quality control \\
& Cost-benefit decisions \\
& Decisions about a program's future \\
& Accreditation/licensing \\
& Formative evaluation \\
& Identification of strengths and weaknesses \\
& Continuous improvement \\
& Quality enhancement \\
& Being a learning organization \\
& More efficient management \\
& Adaptation of a model locally \\
& Generalizations about effectiveness \\
& Extrapolation of principles about what works \\
& Theory building \\
& Synthesizing of patterns across programs \\
& Scholarly publishing \\
& Policy making \\
&
\end{tabular}

(from Patton, 1997, p. 76)

The ultimate aim of the programme is to improve student achievement in numeracy through building teacher capability. But this involves a successful implementation and a sound and sensible policy which "supports and reinforces accomplishing desired program goals" (Patton, 1997, p. 95). Patton, for example, described the principle underlying intervention-orientated evaluation as "to build a program delivery model that logically and meaningfully interjects data collection in ways that enhance achievement of program outcomes, while also meeting evaluation information needs" (p. 95). It has been a challenge in the implementation to remain realistic about progress and the evidence for change in teachers' practice and student results. Patton
(1997) cautions about interpreting results in terms of causal links. Triangulation of research evidence, observation, action research and anecdotal evidence gathered in the field and formal project evaluations have all been employed. The evaluations have also been used to judge the merit of the programme in terms of quality control.

The ways in which the evaluation findings have been used to improve the programme include most of the examples given by Patton. Strengths such as the in-class modelling by facilitators and the emphasis on the discussion of mathematical ideas in teacher-led group sessions have been further developed as the project has progressed. The use of the findings for raising quality, such as the need to support teachers in Māori-medium settings, both in their use of te reo and in their understanding of mathematics, have led to additional resourcing through the project Te Poutama Tau (see evaluation by Christensen, 2003). The strengths and weaknesses identified through questionnaires, and through interviews and observations, have fed back into the programme through an ongoing cycle of local, regional and national meetings.

The third use of evaluation findings is that of generating knowledge (Patton, 1997). Particular aspects of the numeracy project evaluation findings have been generalised to other professional development initiatives. A developing theory about facilitation has suggested that its effectiveness incorporates the interrelated components of facilitators' knowledge of mathematics, their pedagogical knowledge, and their knowledge of learners' cognitions in mathematics. These form the facilitators' context of practice that is underpinned by facilitators' beliefs about effective professional development (Higgins, 2002a).

Characteristics common to effective teachers of numeracy have been identified through the three themes of general characteristics, planning practices, and classroom interactions (Thomas \& Ward, 2002). Further work on classroom practice has investigated interaction patterns in teacher-led groups (Higgins, 2003a). Investigation of a lesson study group based on a Japanese model examined this approach as a context for in-depth professional development for teachers (Thomas, Tagg \& Ward, 2003). As the Numeracy Development Project continues, a shift is evident in the use of the evaluation findings towards generating knowledge (Patton, 1997). It is at this point that there is a change in emphasis from evaluation to research. This is part of the iterative process of evidence-based policy formulation in which there is a constant refining of what counts as evidence of "successful" implementation. 


\section{Summary}

This article has described the development of a Ministry of Education policy which led to a national programme called the Numeracy Development Project. It is argued that the policy process provided a good example of Rist's (1998) outline of a dynamic and evolutionary procedure, which allowed mid-course corrections and incorporated the knowledge and experience of a wide range of people outside the Ministry in review and revision of the policy. The project was evaluated on the improvement it brought about in students' numeracy and on the new knowledge it generated (Patton, 1997). The policy, in turn, was evaluated for its merit or worth according to each phase of its development, and the results were fed back into policy adjustments in an iterative fashion.

Note

The evaluations referred to in this article were funded by the Ministry of Education as part of the Government's Literacy and Numeracy Strategy. The views expressed in this article do not necessarily represent those of either the Ministry or Wellington College of Education.

\section{Acknowledgements}

As author of this article, I would like to acknowledge the considerable assistance in terms of discussion and documentation of Ro Parsons, senior policy analyst and Malcolm Hyland curriculum facilitator at the Ministry of Education. Both have responsibility for the policy development and implementation of the Numeracy Development Project.

\section{References}

Anthony, G. \& Walshaw, M. (2003). Pizza for dinner: "How much" or "How many"? In L. Bragg, C. Campbell, G. Herbert, \& J. Mousley (Eds.), MERINO Mathematics education research: Innovation, networking, opportunity (Vol.2) (pp. 444-451). Proceedings of the 26th Annual Conference of MERGA, July 2003, Geelong, Victoria.

Askew, M., Brown, M., Rhodes, V., Johnson, D., \& Wiliam, D. (1997). Effective teachers of numeracy. London: King's College.

Bobis, J. (1999, December). The impact of Count Me In Too on the professional knowledge of teachers. A report prepared on behalf of the NSW Department of Education \& Training.

Christensen, I. (2003). An evaluation of Te Poutama Tau 2002. Exploring Issues in Mathematics Education. Wellington: Learning Media.
Darling-Hammond, L., \& Sykes, G. (Eds.). (1999). Teaching as the learning profession: Handbook of policy and practice. San Francisco: Jossey-Bass.

Department of Education and Training, New South Wales. (1998). Count Me In Too: Learning framework in number. New South Wales: Department of Education and Training.

Education Review Office. (1994). Mathematics in the New Zealand curriculum: Implementing the 1993 mathematics curriculum in schools. No.1, Autumn. Wellington: Education Review Office.

Else, A. (Ed.). (1999). Exploring issues in mathematics education. Proceedings of a Research Seminar on Mathematics Education (Year 0-6 students). Held at the Ministry of Education on June 12, 1998. Wellington: Ministry of Education, Research and Curriculum Divisions.

Flockton, L., \& Crooks, T. (1997). Mathematics Assessment Results, 1997. National Education Monitoring Report 9. Dunedin: Educational Assessment Research Unit.

Fullan, M. (1999). Change forces: The sequel. London: Falmer Press.

Fullan, M. (2001). The NEW meaning of educational change (3rd ed.). New York: Teachers College Press.

Garden, R. (Ed.). (1997). Mathematics \& science performance in middle primary school: Results from New Zealand's participation in the Third International Mathematics and Science Study (TIMSS). Wellington: Ministry of Education, Research and International Section.

Gilmore, A. (1994). Mathematics and science in the National Curriculum: Evaluation of the teacher development programmes. Christchurch: University of Canterbury, Education Department.

Greene, J. (1998). Qualitative program evaluation. In N. Denzin \& Y. Lincoln (Eds.), Collecting and interpreting qualitative materials (pp. 372-399). Thousand Oaks, CA: Sage.

Higgins, J. (2001). An evaluation of the Year 4 - 6 Numeracy Exploratory Study: Exploring Issues in Mathematics Education. Wellington: Learning Media.

Higgins, J. (2002a). An evaluation of the Advanced Numeracy Project 2001: Exploring Issues in Mathematics Education. Wellington: Learning Media.

Higgins, J. (2002b, April). Tapping into elementary school teachers' pedagogical content knowledge in mathematics. Poster presentation to American Education Research Association, New Orleans. 
Higgins, J. (2003a). An evaluation of the Advanced Numeracy Project 2002: Exploring Issues in Mathematics Education. Wellington: Learning Media.

Higgins, J. (2003b, April). How teachers learn about new practices in mathematics. Paper presented to the American Education Research Association, Chicago.

Holton, D., Spicer, T., Thomas, G., \& Young, S. (1996). The benefits of problem solving in the learning of mathematics. Final Report to the Ministry of Education. Wellington: Ministry of Education, Research and International Section.

Hughes, P. (2002, July) A model for teaching numeracy strategies. In B. Barton, K. Irwin, M. Pfannkuch \& M. Thomas (Eds.), Mathematics Education in the South Pacific (Vol.1) (pp. 350-357). Proceedings of MERGA 25, Auckland.

Hughes, P., \& Petersen, L. (2003, July). Constructing and using a personal numeracy teaching model in a classroom setting. In L. Bragg, C. Campbell, G. Herbert, \& J. Mousley (Eds.), MERINO Mathematics education research: Innovation, networking, opportunity (Vol. 2) (pp. 444-451). Proceedings of the 26th Annual Conference of MERGA, Geelong, Victoria.

Irwin, K., \& Neiderer, K. (2002). An evaluation of the numeracy exploratory study Years 7-10, 2001: Exploring Issues in Mathematics Education. Wellington: Learning Media.

Irwin, K. (2003). An evaluation of the numeracy project for Years 7-10, 2002: Exploring Issues in Mathematics Education. Wellington: Learning Media.

Ministry of Education. (1992). Mathematics in the New Zealand Curriculum. Wellington: Ministry of Education.

Ministry of Education. (1993). The New Zealand Curriculum Framework. Wellington: Ministry of Education.

Ministry of Education. (1997). Report of the Mathematics and Science Taskforce. Wellington: Ministry of Education.

Ministry of Education. (2000). The National Administration Guidelines. Wellington: Learning Media.

Ministry of Education. (2001, February). The numeracy story. Curriculum Update, 45.

Ministry of Education. (2002). The number framework: Draft teachers' materials. Wellington: Learning Media.
Parsons, R. (2001, December). Professional development: Improving teaching capability. Paper presented to Numeracy Hui, Auckland College of Education.

Patton, M. Q. (1997). Utilization-focused evaluation: The New Century Text (3rd ed.). Thousand Oaks, CA: Sage.

Putnam, R., \& Borko, H. (1997). Teacher learning: Implications of new world views of cognition. In B. Biddle, T. Good \& I. Goodson (Eds.), International handbook of teachers and teaching (Vol. 2) (pp. 1223-1296). Netherlands: Kluwer.

Rist, R. (1998). Influencing the policy process with qualitative research. In N. Denzin \& Y. Lincoln (Eds.), Collecting and interpreting qualitative materials (pp.400-424). Thousand Oaks, CA: Sage.

Thomas, G., Tagg, A., \& Ward, J. (2002, July). Making a difference: The Early Numeracy Project. Keynote address to MERGA 25, Auckland.

Thomas, G., Tagg, A., \& Ward, J. (2003). An evaluation of the Early Numeracy Project, 2002: Exploring Issues in Mathematics Education. Wellington: Ministry of Education.

Thomas, G., \& Ward, J. (2001). An evaluation of the Count Me In Too pilot project: Exploring Issues in Mathematics Education. Wellington: Ministry of Education.

Thomas, G., \& Ward, J. (2002). An evaluation of the Early Numeracy Project, 2001: Exploring Issues in Mathematics Education. Wellington: Ministry of Education.

Wright, R. (1998). An overview of a research-based framework for assessing and teaching early number. In C. Kanes, M. Goos \& E. Warren (Eds.), Proceedings of the 21st Annual Conference of the Mathematics Education Group of Australasia (Vol. 2) (pp. 701-708). Brisbane: Griffiths University.

Wright, V. (2003, July). Assessing generalisation of advanced multiplicative strategies. In L. Bragg, C. Campbell, G. Herbert, \& J. Mousley (Eds.), MERINO Mathematics education research: Innovation, networking, opportunity (Vol. 2) (pp. 760-767). Proceedings of the 26th Annual Conference of MERGA, Geelong, Victoria.

Young-Loveridge, J., \& Wright, V. (2002, July). Validation of the N.Z. Number framework. In B. Barton, K. Irwin, M. Pfannkuch \& M. Thomas (Eds.), Mathematics Education in the South Pacific (Vol. 2) (pp. 722-729). Proceedings of MERGA 25, Auckland.

Young-Loveridge, J. \& Taylor, M. (2003, July). The perspectives of two children who participated in the Advanced Numeracy Project. In L. Bragg, C. Campbell, G. Herbert, \& J. Mousley (Eds.), MERINO Mathematics education research: Innovation, networking, opportunity (Vol. 2) (pp. 776-782). Proceedings of the 26th Annual Conference of MERGA, Geelong, Victoria. 
The Author

Joanna Higgins is a teacher educator and researcher at Wellington College of

Education, Te Whanau O Ako Pai Ki Te Upoko O Te Ika, and one of the evaluators

of the Numeracy Development Project.

Please address correspondence to: joanna.higgins@wce.ac.nz 